\title{
The origin and architecture of existential indeterminates in Okinawan
}

\author{
Ken Hiraiwa*
}

\begin{abstract}
In a number of languages, an indeterminate is combined with various particles to yield different indefinite pronouns. This has been called an indeterminate system (Kuroda 1965, Cheng 1991, Haspelmath 1997, Jayaseelan 2001). As Haspelmath (1997) and Jayaseelan (2001) observe, existential indeterminates are often built with disjunction markers. On the other hand, a disjunction particle and a question particle are often morphologically identical cross-linguistically (see Hagstrom 1998, Jayaseelan 2001). Thus, a question that I ask here is whether the alleged homophony between a disjunction marker and a marker that forms an existential quantifier is principled (Jayaseelan 2001, Szabolcsi et al. 2014) or coincidental (Haspelmath 1997, Cable 2010). In this paper, I argue that the observation about homophony is misguided and hence support Haspelmath's hypothesis, based on the data obtained from my fieldwork on Okinawan, an endangered Ryukyuan language. I propose an analysis where existential indeterminates in Okinawan have a clausal structure of an embedded question and are derived by deletion.
\end{abstract}

Keywords. indeterminates; existential quantifiers; question; disjunction; deletion

1. Introduction. In a number of languages, an indeterminate is combined with various particles to yield different indefinite pronouns. This has been called an indeterminate system (Kuroda 1965, Cheng 1991, Haspelmath 1997, Jayaseelan 2001). In Malayalam, Japanese, and Nanay, for example, an indeterminate 'who' is interpreted as existential 'someone', when combined with a disjunction particle (1b-3b). In Basque and Russian, an indeterminate 'who' receives a free choice interpretation when combined with a disjunction particle (4b-5b) (the data are cited from Haspelmath1997).

(1) a. aarə 'who' b. aar(ə)-оo 'someone'

(2) a. dare 'who' b. dare-ka 'someone'

(Malayalam)

(3) a. uj 'who' b. uj-nuu 'someone'

(Japanese)

(Nanay)

(4) a. nor 'who' b. edo-nor 'whoever'

(Basque)

(5) a. kto 'who' b. kto-libo 'whoever'

(Russian)

As Haspelmath (1997) and Jayaseelan (2001) observe, existential indeterminates and free choice indeterminates are often built with disjunction markers. On the other hand, a disjunction particle and a question particle are often morphologically identical cross-linguistically (see Hagstrom 1998, Jayaseelan 2001). Thus, a question that I ask here is whether the alleged homophony between a disjunction marker and a marker that forms an existential quantifier is principled

\footnotetext{
* I am very grateful to Mrs. Chie Inamine for the Naha/Shuri Okinawan data and her insightful observations, without which this project would never have been possible. I would like to thank Michael Yoshitaka Erlewine, Chris Davis, Kimiko Nakanishi, Shinsho Miyara, and Akira Watanabe for helpful comments and/or questions at various stages of this and related projects. This research has been funded by the JSPS Grant-in-Aid for Scientific Research (C) (No. 16K02645), to which I am grateful. $\mathrm{C}=$ complementizer, $\mathrm{COND}=$ conditional, $\mathrm{COP}=$ copula, $\mathrm{DAT}=$ dative, $\mathrm{FOC}=$ focus particle, $\mathrm{HS}=$ hear-say, $\mathrm{IMP}=$ imperative, $\mathrm{IND}=$ indicative, $\mathrm{NEG}=$ negation, $\mathrm{NOM}=$ nominative, $\mathrm{PST}=$ past tense, $\mathrm{PRS}=$ present tense, $\mathrm{Q}=$ question particle, $\mathrm{SFP}=$ sentence-final particle, $\mathrm{TOP}=$ topic. Author: Ken Hiraiwa, Meiji Gakuin University (hiraiwa@1tr.meijigakuin.ac.jp).
} 
(Jayaseelan 2001, Szabolcsi et al. 2014) or coincidental (Haspelmath 1997). In this paper, I argue that the observation about homophony is misguided and hence support Haspelmath's hypothesis, based on the data obtained from my fieldwork on Okinawan, an endangered Ryukyuan language. I propose an analysis where existential indeterminates in Okinawan have a clausal structure of an embedded question and are derived by deletion.

2. Indeterminates in Okinawan. Japanese has an indeterminate system (Kuroda 1965, 2013, Shimoyama 2008, Hiraiwa 2015, 2017). Okinawan also has an indeterminate system, just as Japanese does (see Sugahara 1996 and Hiraiwa 2019; see Miyara 2000, 2015b, 2019 for a general grammatical description of Okinawan). Each of the five indefinite pronouns in Okinawan combines an indeterminate pronoun and one of the quantificational particles $(\varnothing / n /$ gana/yatin $){ }^{1}$

\begin{tabular}{lccccc} 
& + nominal & + nominal & +nominal & -nominal & -nominal \\
\hline & Wh & Universal & Existential & NPI & Free Choice \\
& 'wh X's & 'every X' & 'some X' & 'any X' & 'wh-ever' \\
\hline who & taa-CASE & taa-CASE -n & taa'-gana-CASE & taa-n & taa'-yatin \\
what & nuu-CASE & nuu-CASE -n & nuu'-gana-CASE & nuu-n & nuu'-yatin \\
where & maa-CASE & maa-CASE -n & maa'-gana-CASE & maa-n & maa'-yatin \\
\hline
\end{tabular}

Table 1. Indeterminate system in Okinawan (partial)

(1) Okinawan who-NOM come-PST Q 'Who came?'
a. Taa-ga choo-ta ga?
b. Taa-ga-n chuu sa. who-NOM-N come SFP 'Everyone will come.'
c. Taa-gana-ga ch-an who-GANA-NOM come-PST 'Someone came.'
d. Taa-n kuu-n-tan. who-N come-NEG-PST 'No one came.'
e. Taa-yatin chuu sa. ${ }^{2}$ who-YATIN come SFP 'Anyone will come.'

3. Absence of a disjunction particle in Okinawan. In Japanese, universal/NPI indeterminates and existential indeterminates are built by combining an indeterminate pronoun and the particles $m o$ and $k a$, respectively (Nishigauchi 1990, Takahashi 2002, Watanabe 2006, Yatsushiro 2008, Uegaki 2018).

\footnotetext{
${ }^{1}$ The [+nominal]/[-nominal] distinction is based on whether case-marking is possible. ' indicates the position of pitch accent. See Hiraiwa $(2015,2017)$ for a detailed analysis of Japanese indeterminates.

${ }^{2}$ Evidently, the morpheme yatin is complex, consisting of the copula yati, and the additive particle $n$. See Section 4 on its clausal status. A similar decompositional analysis will be proposed for gana, too. See also Hiraiwa \& Nakanishi (to appear) for arguments that free choice indeterminates (e.g., dare-demo 'whoever') are syntactically an unconditional clause, exactly in the same way as taa-yati-n 'whoever' in Okinawan.
} 
(2) Japanese
a. dare
'who'
b. dare-mo
'any/everyone
c. Taro-mo
'Taro, too'

(3) Japanese
a. dare
'who'
b. dare-ka
'someone'
c. Taro-ka Hanako-ka
'Taro or Hanako'

While it has an additive conjunction particle $n$ (the cognate of mo 'also' in Japanese), which is used to build a universal quantifier and an NPI, Okinawan lacks a simple morpheme that expresses nominal disjunction and the morpheme gana used for building existential indeterminates does not have a disjunctive function.

(4) Okinawan
a. taa
'who'
b. taa-n
'any/everyone'
c. Taraa-n
'Taraa, too'

(5) Okinawan
a. taa
'who'
b. taa-gana
'someone'
c. *Taraa-gana Maziruu-gana
'Taraa or Maziruu

On the other hand, the language does have a sentence-final question particle $g a$ (for wh-question) and ( $m) i$ (for yes-no question), as (6a) indicates. This question particle is distinct from the yes-no question particle - $m i$ as shown in (6b). Importantly, however, these particles cannot build an existential indeterminates (or disjoin phrases), either, as shown in (7).

(6) Okinawan

a. Taa-ga ichu ga?

who-NOM go Q

'Who will go?'

b. Jiraa-ga ichu mi?

Jiraa-NOM go Q

'Does Jiraa go?'

(7) Okinawan

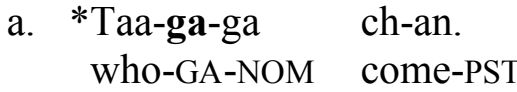
'Someone came.'
b. *Taa-mi-ga ch-an. who-MI-NOM come-PST
'Someone came.'
c. *Taraa-ga Maziruu-ga
Taraa-GA Maziruu-GA
'Taraa or Maziruu'




\section{d. *Taraa-(m)i Maziruu-(m)i \\ Taraa-MI Maziruu-MI \\ 'Taraa or Maziruu'}

Clausal disjunction in alternative question in Okinawan does not employ any overt marker.

(8) Okinawan

Shinshi-ya Taraa-nkai [ichu-mi ika-n-i] chich-an.

teacher-TOP Taraa-DAT go-Q go-PRS-NEG-Q ask-PST

'The teacher asked Taraa whether he would go or not go.'

\begin{tabular}{lccccc} 
& $\begin{array}{c}\text { nominal } \\
\text { disjunction }\end{array}$ & $\begin{array}{c}\text { clausal } \\
\text { disjunction }\end{array}$ & wh-question & $\begin{array}{c}\text { yes-no } \\
\text { question }\end{array}$ & existential \\
\hline Japanese & $\mathbf{k a}$ & $\varnothing$ & $\mathbf{k a}$ & $\mathbf{k a}$ & $\mathbf{k a}$ \\
Okinawan & - & $\varnothing$ & $\mathbf{g a}$ & $\mathbf{m i}$ & $\mathbf{g a n a}$ \\
\hline
\end{tabular}

Table 2. disjunction, question, and existential markers in Japanese and Okinawan

These facts show that (i) Okinawan lacks a disjunction particle and hence that (ii) its question markers cannot build existential indeterminates, contrary to the languages listed in (1).

4. Existential indeterminates in Okinawan as clausal questions. As noted in the previous sections, existential indeterminates in Okinawan employ the mysterious morpheme gana, which is not a disjunction particle.

(9) Okinawan

Taa-gana-ga ch-an.

who-GANA-NOM come-PST

'Someone came.'

Although the morpheme gana is likely to be composed of the Q-particle $g a$ and $n a$, the status of the latter is not immediately clear. Putting aside gana for a moment, it is interesting to look at another form of existential indeterminate in Okinawan, as shown in (10).

(10) Okinawan

Taa-gayara ch-an.

who-GAYARA come-PST

'Someone came.'

Importantly, this form is identical to an embedded self-question structure, as shown in (11). ${ }^{3} \mathrm{Ev}-$ idently, gayara in (11) is syntactically complex: $g a$ is a Q-complementizer, yara is a conditional form of copula.

(11) Okinawan

a. [Taa ga ya-ra] wakara-n.

who Q COP-RA know-NEG.PRS

'I don't know who it is.'

${ }^{3}$ von Fintel \& Iatridou (2019) discuss particles that make questions "unasked questions". It is interesting that existential indeterminates are derived from unasked question forms (or self-question forms) both in Okinawan and Japanese. See Section 5 (especially, examples (22)-(23)) and Hiraiwa \& Nakanishi (to appear) on Japanese. 


\section{b. Taa ga ya-ra. \\ who Q COP-RA \\ '(I wonder/I don't know) Who it is.'}

As described in detail in Miyara (2000, 2007, 2015a), Karimata \& Shimabukuro (2007), Shinzato \& Serafim (2013), van der Lubbe (2017), wh-question and self-question are syntactically distinct in Okinawan. The latter takes a form of focus-concord construction (called kakarimusubi). ${ }^{4}$

(12) Okinawan
a. $\{\mathrm{Taa} / * \mathrm{Taraa}\}$-ga choo-ta ga?
who/Tara-NOM come-PST Q
'Who came? / *Did Tara come?'
b. $\{$ Taa/Taraa $\}$-ga-ga choo-ta-ra? who/Tara-NOM-Q come-PST-RA
'I wonder who came. / I wonder if Tara came.' (Focus-concord self-question)
(Wh-question)

Wh-question in (12a) is information-seeking. The Q-particle appears at the end of the clause as a Q-complementizer and requires a wh-phrase. In contrast, focus-concord question in (12b) is a self-question and hence not information-seeking. The Q-particle $g a$ necessarily attaches to the focus of the sentence and the predicate takes the focus-concord suffix -ra (see Miyara 2000, 2007, 2015a for a detailed description). Thus, the existential indeterminate in (10) and the selfquestion in (11) are both derived from the focus-concord question construction in (12b).

Interestingly, Okinawan employs this self-question structure in (11) and (12b) to build the existential indeterminate in (10). More specifically, I propose that what looks like an existential indeterminate in (10) is derived from an embedded self-question 'I wonder / don't know wh- it is' by dunno-deletion and question-internal ellipsis (or pseudo-sluicing) inside the embedded question (Ross 1969; see, Inamine 2005, Miyara 2007, and Kurafuji 2009 on sluicing in Okinawan, and Saito 2007 and Hiraiwa \& Ishihara 2010 on (pseudo)-sluicing in Japanese), as illustrated in (13)-(14). ${ }^{5}$

(13) Okinawan

[Uree Taa ga ya-ra] wakara-n shiga, chuu ndi doo. it.TOP who Q COP-RA know-NEG but come C.say SFP

'I heard that someone would come.' (lit.) I don't know who it is, (I heard) (he/she) will come.'

\footnotetext{
${ }^{4}$ While the sentence-final Q-complementizer $g a$ in Okinawan in (12a) requires a wh-phrase, the Q-particle $g a$ in (12b) does not.

5 gayara, yarawan, and yatin are not always interchangeable, as the latter two are unconditional/free choice forms.
}

(i) Okinawan

Koohii- $\{$ yatin/*gayara $\}$ ucha- $\{$ yatin/*gayara $\}$ kwimisooree.

coffee- YATIN/GAYARA tea-YATIN/GAYARA give.me.please.IMP

'Please give me some coffee or tea.' 
(14) Okinawan

[Uree Taa ga ya-ra] wakara-n shiga, chuu ndi doo. it.TOP who Q COP-RA know-NEG but come C.say SFP

'I heard that someone would come.' (lit.) I don't know who it is, (I heard) (he/she) will come.'

The predicate wakara-n (shiga) 'I don't know', which takes the embedded self-question, is deleted. The embedded question has the following structure in (15). The topicalized nominal demonstrative, which refers to the antecedent clause, undergoes ellipsis. The Q-particle attaches to the wh-phrase taa 'who' and agrees with the sentence-final focus-suffix -ra (focus concord).

(15) Iden't know who it is, but ...

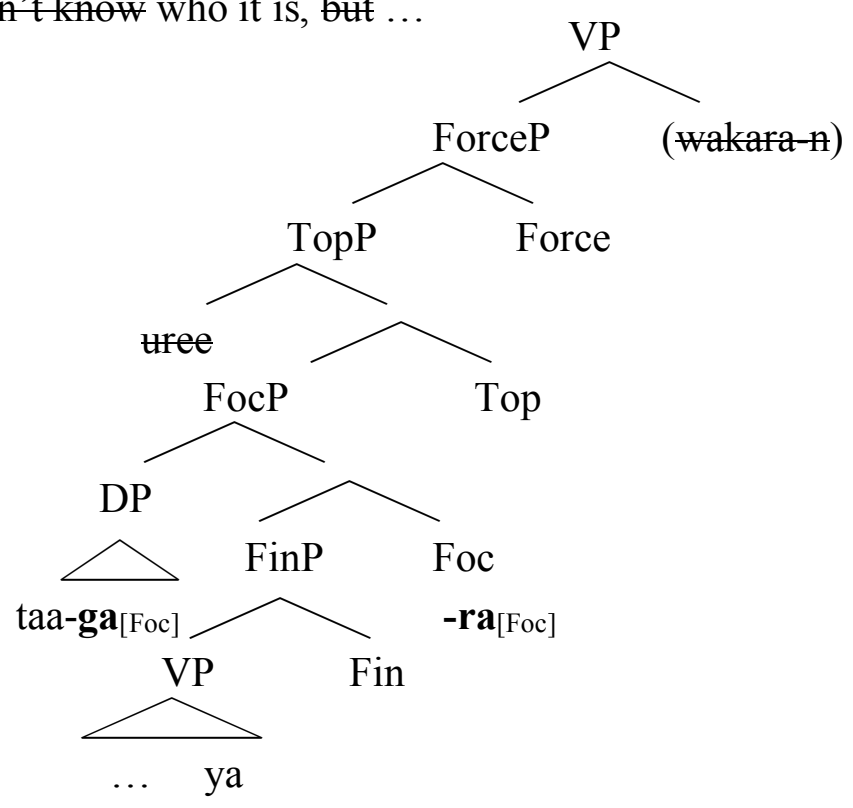

Haspelmath makes an important observation that existential quantifiers in some European languages have a sentential structure 'I don't know who', as their source. This is illustrated in (16).

(16) Haspelmath $(1997,131)^{6}$
a. neizwer 'somebody' <ne weiz wer '(I) don't know who'
(Middle High German)
b. nāthwā 'somebody' <newāt hwā '(I) don't know who'
(Old English)
c. nekkver 'somebody' <*ne wait ik hwarir 'I don't know who'
(Old Norse)
d. neștine 'some' <Latin: nescio quis 'I don't know who'
(Romanian (dialectal))
e. na(m)koj 'somebody' <ne znam koj'I don't know who'
(Bulgarian (dialectal))

${ }^{6}$ Another way to build an existential indeterminate is reduplication.
(i)
a. Taa-taa-ya kuu-n-tan.
who-who-TOP come-NEG-PST
'(I don't know their name, but) a certain person/certain people didn't come.'
$\begin{array}{lll}\text { b. } & \text { *Taa-gana taa-gana-ya kuu-n-tan. } \\ \text { who-GANA who-GANA-TOP come-NEG-PST }\end{array}$
'(I don't know their name, but) a certain person/certain people didn't come.'

As the translations indicate, it seems that reduplicated indeterminates is specific-unknown. Reduplicated indeterminates are also possible with universal indeterminates and NPIs. (e.g., taa-ga- $n$ ta-ga- $n$ 'everyone', taa- $n$ taa- $n$ 'anyone'). 
f. někǔto 'somebody' <ne vě kǔto 'I don't know who' (Old Church Slavonic)

g. je ne sais quel 'some kind of' <cf. je ne sais (pas) quel 'I don't know which' (French)

Haspelmath refers to this type of grammaticalization path of existential quantifiers as dunno-type and observes that it is restricted to the European languages, but our analysis in (13)-(14) demonstrates that it is a general mechanism, observed outside the particular language family (see also Section 5 on Japanese).

I argue that the lack of a disjunction particle and the question-based existential indeterminates provide strong evidence against the homophony between a disjunction particle and a particle that forms existential indeterminates. Rather, it must be the Q-complementizer that plays a crucial role in deriving existential indeterminates in Okinawan. ${ }^{7}$

Finally, let us return to gana. As mentioned at the beginning of this section, $g a$ should be a Q-particle of a focus-concord question. I propose that gana is derived from ga ya-ra in (17).

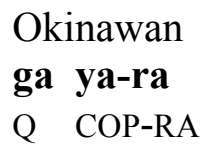

Suppose that the underlying structure of taa-gana 'someone' is taa ga ya-ra in (14). If deletion applies to the copula ya alone, leaving the focus-concord suffix intact, then we obtain the form *taa-gara in (17b). Assuming that $/ \mathrm{r} /$ undergoes phonological change to $/ \mathrm{n} /$, we obtain the form taa-gana in (17c).
a. taa ga ya-ra '(I wonder) who it is'
b. taa ga ya-ra copula deletion
c. taa ga yana $/ \mathrm{r} / \rightarrow / \mathrm{n} /$

The phonological fortition rule in (18c) is common cross-linguistically (see Proctor 2009) ${ }^{8}$. van der Lubbe (2017) observes that the form gara in (18b) is indeed employed in an embedded (self)-question in Okinoerabu Ryukyuan (see also van der Lubbe \& Tokunaga 2015).

(19) Okinoerabu Ryukyuan (Van der Lubbe 2017, 303) $)^{9}$

Ichi ki-n gara waka-ra-n.

when come-IND GARA know-NEG-IND

'I don't know when he will come.'

Furthermore, the analysis in (18) is also independently supported by the fact that the counterpart of gana in Irabu is gagara (see footnote 7). ${ }^{10}$

\footnotetext{
${ }^{7}$ Shimoji (2008) observes similar data, wh-gagara (or wh-gara), from Irabu, a southern Ryukyuan language. If my analysis of Okinawan and Japanese is on the right track, then question-based existential indeterminates may well be a wide-spread feature of the languages across Japan. I suspect that the doubling $g a$ in Irabu is due to noncomplementary distribution of the Q-particle $g a$ and the Q-complementizer $g a$ in wh-focus-concord question in Irabu (see Shimoji 2008, 447-448).

(i) Irabu (Shimoji 2008, 242-243)

Tau-gagara-nu-du sïn-tar-ca.

who-GAGARA-NOM-FOC die-PST-HS

'Someone has died, they say.'

${ }^{8}$ Thanks to Feng-Fan Hsieh for bringing this to my attention. The existence of glide-nasal alternation is also observed in Irabu (see Shimoji 2008, 448).

${ }^{9}$ Thanks to Chris Davis for bringing my attention to the dialectal data.
} 
5. Japanese existential indeterminates as embedded question. The analysis of existential indeterminates as hidden embedded question is corroborated by Japanese. Nakanishi \& Hiraiwa (2019) and Hiraiwa \& Nakanishi (to appear) argue that there is indeed evidence that they are clausal in its origin and the particle $k a$ is a Q-complementizer. The existential indeterminate dare-ka in example (20a) has long been considered to be an indeterminate combined with a nominal disjunction particle $k a$. However, we also find a semantically equivalent clausal expression (20b) in Japanese, just like in Okinawan. If we apply dunno-deletion, we obtain (20). If the copula is further deleted, we obtain the form (20d), which is identical to (20a).

(20) Japanese (Hiraiwa \& Nakanishi to appear)
a. [Dare-ka]-ga kit-ta. who-KA-NOM come-PST
'Someone came.'
b. [Dare dat-ta ka] shira.nai-ga ki-ta. who COP-PST Q know.NEG-but come-PST 'Someone (lit. I don't know who it was) came.'
c. [Dare dat-ta ka] shira.nai-ga ki-ta. who COP-PST Q know.NEG-NOM come-PST 'Someone (lit. I don't know who it was) came.'
d. [Dare dat-ta
ka] shira.nai-ga ki-ta. who COP-PST Q know.NEG-NOM come-PST 'Someone (lit. I don't know who it was) came.'

Crucially, Japanese has another existential indeterminate expression (21), where only the sentential negation is elided from (20b) (with optional copula deletion).

(21) Japanese
a. [Dare dat ka] shira-nai ga ki-ta. who COP-PST Q know.NEG NOM come-PST 'Someone (lit. I don't know who) came.'
b. [Dare dat-ta ka] shira-nai ga ki-ta. who COP-PST Q know.NEG NOM come-PST 'Someone (lit. I don't know who) came.'

${ }^{10}$ Incidentally, this form, ga ya-ra can also convey disjunction.

(i) Kunu sumuchee, [Taraa mun ga ya-ra], [Jiraa mun ga ya-ra], ya sa. this book Taraa thing COP-RA Jiraa thing Q COP-RA COP SFP 'This book is Taraa's or Jiraa's.' '(lit.) This book is, I wonder if it is Taraa's or if it is Jiraa's.'

Two other forms yarawan and yatin can also be used for expressing what amounts to disjunction. They are also concessive conditional (or unconditional) clauses and the latter is also used as free choice expression (see table 1).

(ii) Okinawan
a. Pan ya-ra-wa-n
bread COP-RA-COND-also
kume ya-ra-wa-n rice COP-RA-TOP-also
masiyasi kara irabee. 'Choose what you like better, whether bread or rice.'
b. Pan yati-n
'Choose what you like better, whether bread or rice.'
bread COP.COND-also rice COP.COND-also better from choose.IMP 
The forms in (21) cannot be explained if $k a$ were a nominal disjunction particle, because then it would not be able to be selected by the verb 'know'.

From the perspective of the proposed analysis of existential indeterminates in Okinawan, the closest Japanese counterpart of the Okinawan example in (14) is (22). ${ }^{11}$

(22) Japanese
a. [Dare yara] ki-ta.
who YARA come-PST
'Someone came.'
b. [Nani yara] ki-ta.
what YAERA come.PST
'Something came.'

Just as the form ga-ya-ra in Okinawan is used as a self-question, the form yara is also used as a self-question in Japanese.

(23) Japanese (Hiraiwa \& Nakanishi to appear, footnote 12)

Dare-ga kuru no yara.

who-NOM come C YARA

'I wonder/don't know who will come.'

6. Conclusion. In this paper, I have demonstrated that existential indeterminates in Okinawan have a clausal structure. The morpheme gana in Okinawan is neither a disjunction particle nor a Q-particle, lending support for the claim that the alleged morphological affinity between disjunction particles and morphemes building existential quantifiers is coincidental. Rather, I have argued that existential indeterminates in Okinawan are syntactically derived from an embedded focus-concord self-question wh-ga...ya ra through dunno-deletion. It is claimed, then, that the form gana has emerged from deletion of the copula $y a$ and liquid-nasal alternation.

\section{References}

Cable, Seth. 2010. The grammar of Q: Q-particles, wh-movement, and pied piping. New York, NY: Oxford University Press.

Cheng, Lisa. 1991. On the typology of wh-question. Cambridge, MA: MIT dissertation. von Fintel, Kai \& Sabine Iatridou. 2019. Unasked questions. A paper presented at WAFL 15. Hagstrom, Paul. 1998. Decomposing questions. Cambridge, MA: MIT dissertation.

Haspelmath, Martin. 1997. Indefinite pronouns. Oxford: Oxford University Press.

Haspelmath, Martin, \& Ekkehard König. 1998. Concessive conditionals in the languages of Europe. In Johan van der Auwera (ed.), Adverbial constructions in the languages of Europe. 563-640. Berlin: Mouton de Gruyter.

Hiraiwa, Ken. 2015. The QP syntax: Noun class, case, and augment. In Thuy Bui \& Deniz Özidiz (eds.), The proceedings of NELS 45, 1-11. Amherst, MA: GLSA.

Hiraiwa, Ken. 2017. Labeling roots: Indeterminates and particles. In Andrew Lamont \& Katerina Tetzloff (eds.), The proceedings of NELS 47, volume 2. 79-88. Amherst, MA: GLSA.

Hiraiwa, Ken, \& Shinichiro Ishihara. 2012. Syntactic metamorphosis: Clefts, sluicing, and in-situ focus in Japanese. Syntax 15(2). 142-180. https://doi.org/10.1111/j.1467-9612.2011.00164.x.

${ }^{11}$ This is another example of bare indeterminates discussed in Nakanishi \& Hiraiwa (2019) and Hiraiwa and Nakanishi (2020). 
Hiraiwa, Ken \& Kimiko Nakanishi. To appear. Japanese free choice and existential indeterminates as hidden clauses. The proceedings of WAFL 15. Cambridge, MA: MITWPL.

Hiraiwa, Ken \& Kimiko Nakanishi. 2020. Bare indeterminates in unconditionals. Proceedings of the Linguistic Society of America (PLSA) 5. 395-409. https://doi.org/10.3765/plsa.v5i1.4706.

Inamine, Seiji. 2005. Okinawago ni okeru wh-gimonbunkanyaku (Wh-question truncation in Okinawan). Nishihara, Okinawa: University of the Ryukyus Master's thesis.

Jayaseelan, K. A. 2001. Questions and question-word incorporating quantifiers in Malayalam. Syntax 4(2). 63-93. https://doi.org/10.1111/1467-9612.00037.

Karimata, Shigeki \& Yukiko Shimabukuro. 2007. Okinawa hoogen no toritate no kuttsuki to kakari musubi: Nakijin Jana hoogen to Gushikawa Agena hoogen no baai (Okinawan-dialect focus particles and kakari musubi, as seen from Nakijin Jana \& Gushikawa Agena dialects). Ryukyu Daigaku Hoobun Gakubu Kiyoo Nihon Toyoo Bunka Ronshuu. 13: 1-29.

Kurafuji, Takeo. 2009. Clausal pied-piping and cyclicity of ellipsis: evidence from truncated whquestions in Okinawan. In Anisa Schardl, Martin Walkow, \& Muhammad Abdurrahman (eds.), The proceedings of NELS 38, vol. 2, 39-48. Amherst, MA: GLSA.

Kuroda, S.-Y. 1965. Generative grammatical studies in the Japanese language. Cambridge, MA: MIT dissertation.

Kuroda, S.-Y. 2013. Prosody and the syntax of indeterminates. Lingua 124. 64-95. https://doi.org/10.1016/j.lingua.2012.10.013

van der Lubbe, Gijs. 2017. Japanese-Northern Ryukyuan and structural convergence: The case of embedded interrogative constructions. In Kenshi Funakoshi, Shigeto Kawahara \& Christopher D. Tancredi (eds.), The proceedings of Japanese/Korean Linguistics 24, 301-314. Stanford, CA: CSLI.

van der Lubbe, Gijs \& Akiko Tokunaga. 2015. Okimoerabu grammar. In Patrick Heinrich, Shinsho Miyara, \& Michinori Shimoji (eds.), The handbook of Ryukyuan languages: History, structure, and use,. 345-378. Berlin: Mouton de Gruyter. https://doi.org/10.1515/9781614511151.345.

Miyara, Shinsho. 2000. Utinaa-guti kooza (Lectures on Okinawan). Naha, Okinawa: Okinawa Times.

Miyara, Shinsho. 2007. On the properties of wh and focus in Okinawan. In Bjarke Frellesvig, Masayoshi Shibatani \& John Charles Smith (eds.), Current issues in the history and structure of Japanese. 187-205. Tokyo: Kurosio Publishers.

Miyara, Shinsho. 2015a. A generative approach to focusing in Okinawan. In Patrick Heinrich, Shinsho Miyara \& Michinori Shimoji (eds.), The handbook of Ryukyuan languages: History, structure, and use. 141-156. Berlin: Mouton de Gruyter. https://doi.org/10.1515/9781614511151.141.

Miyara, Shinsho. 2015b. Shuri Okinawan grammar. In Patrick Heinrich, Shinsho Miyara \& Michinori Shimoji (eds.), The handbook of Ryukyuan languages: history, structure, and use. 379-404. Berlin: Mouton de Gruyter. https://doi.org/10.1515/9781614511151.379.

Miyara, Shinsho. 2019. Utinaaguti: Sikumi to kaisetu (Okinawan: Its grammar and explanation). Okinawa Jiji Shuppan.

Nakanishi, Kimiko, \& Ken Hiraiwa. 2019. Nihongo no hadaka huteego: Zyoohozyookensetu ni okeru ninka mekanizumu o toosite (Bare indeterminates in Japanese: A view from a licensing mechanism in unconditionals). In Osamu Sawada, Hideki Kishimoto \& Ikumi Imani (eds.), Hiteehyoogen no koozoo, imi, kinoo (The structure, meaning, and function of negative expressions). 154-179. Tokyo: Kaitakusya. 
Nishigauchi, Taisuke. 1990. Quantification in the theory of grammar. Dordrecht: Kluwer Academic Publishers.

Proctor, Michael. 2009. Gestural characterization of a phonological class: The liquids. New Haven, CT: Yale University dissertation.

Rawlins, Kyle. 2008. (Un)conditionals: An investigation in the syntax and semantics of conditional structures. Santa Cruz, CA: University of California dissertation.

Rawlins, Kyle. 2013. Unconditionals. Natural Language Semantics 40. 111-178. https://doi.org/10.1007/s11050-012-9087-0.

Ross, John Robert. 1969. Guess who? In Robert I. Binnick, Alice Davison, Georgia M. Green \& James L. Morgan (eds.), The proceedings of CLS 5, 252-286. Chicago: Chicago Linguistic Society.

Saito, Mamoru. 2004. Ellipsis and pronominal reference in Japanese clefts. Nanzan Linguistics 1. 21-50.

Shimoji, Michinori. 2008. A grammar of Irabu, a southern Ryukyuan language. Canberra: The Australian National University dissertation.

Shimoyama, Junko. 2008. Indeterminate pronouns. In Shigeru Miyagawa \& Mamoru Saito (eds.), The Oxford handbook of Japanese linguistics, 372-393. New York, NY: Oxford University Press. https://doi.org/ 10.1093/oxfordhb/9780195307344.013.0014.

Shinzato, Rumiko \& Leon A. Serafim. 2013. Synchrony and diachrony of Okinawan kakari musubi in comparative perspective with Premodern Japanese. Leiden: Brill.

Szabolcsi, Anna, James Doh Whang \& Vera Zu. 2014. Quantifier words and their multifunctional(?) parts. Language \& Linguistics 15(1). 115-155. https://doi.org/10.1177/1606822X13506660.

Sugahara, Mariko. 1996. Shuri Okinawan kakari-musubi and movement. In Masatoshi Koizumi, Masayuki Oishi \& Uli Sauerland (eds.), MITWPL \#29: The proceedings of Formal Approaches to Japanese Linguistics 2. 235-254. Cambridge, MA: MITWPL.

Takahashi, Daiko. 2002. Determiner raising and scope shift. Linguistic Inquiry 33(4). 575-615. https://doi.org/10.1162/002438902762731772.

Uegaki, Wataru. 2018. A unified semantics for the Japanese Q-particle $k a$ in indefinites, questions and disjunctions. Glossa 3. 413-450. https://doi.org/10.5334/gjg1.238.

Watanabe, Akira. 2006. Functional projections of nominals in Japanese: Syntax of classifiers. Natural Language \& Linguistic Theory 24(1). 241-306. https://doi.org/10.1007/s11049-0053042-4.

Yatsushiro, Kazuko. 2009. The distribution of quantificational suffixes in Japanese. Natural Language Semantics 17. 141-173. https://doi.org/10.1007/s11050-009-9044-8. 